\title{
Future prevalence of type 2 diabetes - a comparative analysis of chronic disease projection methods
}

Authors: Dina Voeltz ${ }^{1,2}$, Thaddäus Tönnies ${ }^{3}$, Ralph Brinks ${ }^{2,3,4}$, Annika Hoyer $^{1}$

${ }^{1}$ Biostatistics and Medical Biometry, Medical School OWL, Bielefeld University, Bielefeld

${ }^{2}$ Department of Statistics, Ludwig-Maximilians-University Munich

${ }^{3}$ Institute for Biometrics and Epidemiology, German Diabetes Center, Leibniz Institute for Diabetes Research at Heinrich-Heine-University Duesseldorf

${ }^{4}$ Chair for Medical Biometry and Epidemiology, Witten/Herdecke University, Faculty of Health/School of Medicine, Witten

Corresponding author: Dina Voeltz, dina.voeltz@uni-bielefeld.de

Keywords: epidemiology; projection methods; chronic disease modelling; illness-death-model; diabetes; 
medRxiv preprint doi: https://doi.org/10.1101/2021.11.25.21266868; this version posted November 26, 2021. The copyright holder for this preprint (which was not certified by peer review) is the author/funder, who has granted medRxiv a license to display the preprint in It is made available under a CC-BY 4.0 International license.

\section{Declarations}

Financial disclosure statement: There are no financial conflicts of interest to disclose. The authors declare that they have no relevant or material financial interests that relate to the research described in this paper.

Data availability statement: The authors confirm that the data supporting the findings of this study are available within the articles of Tamayo et al. [23], Schmidt et al. [2] and their respective supplementary materials. Other data about the population projections used in this study are openly available from the FSO [20]. We provide our complete R-code and underlying data sets for reproducing the analysis in the supporting information. 
medRxiv preprint doi: https://doi.org/10.1101/2021.11.25.21266868; this version posted November 26, 2021. The copyright holder for this preprint (which was not certified by peer review) is the author/funder, who has granted medRxiv a license to display the preprint in It is made available under a CC-BY 4.0 International license.

\section{Abstract}

Background Accurate projections of the future number of people with chronic diseases are necessary for effective resource allocation and health care planning in response to changes in disease burden.

Aim To introduce and compare different projection methods to estimate the number of people with diagnosed type 2 diabetes (T2D) in Germany in 2040.

Methods We compare three methods to project the number of males with T2D in Germany in 2040. Method 1) simply combines the sex- and age-specific prevalence of T2D in 2010 with future population distributions projected by the German Federal Statistical Office (FSO). Methods 2) and 3) additionally account for the incidence of T2D and mortality rates using partial differential equations (PDEs). Method 2) models the prevalence of T2D employing a scalar PDE which incorporates incidence and mortality rates. Subsequently, the estimated prevalence is applied to the population projection of the FSO. Method 3) uses a two-dimensional system of PDEs and estimates future case numbers directly while future mortality of people with and without T2D is modelled independently from the projection of the FSO.

Results Method 1) projects 3.6 million male people with diagnosed T2D in Germany in 2040. Compared to 2.8 million males in 2010 , this equals an increase by $29 \%$. Methods 2) and 3) project 5.9 million (+104\% compared to 2010$)$ and 6.0 million (+116\%) male T2D patients, respectively.

Conclusions The results of the three methods differ substantially. It appears that ignoring temporal trends in incidence and mortality may result in misleading projections of the future number of people with chronic diseases. Hence, it is essential to include these rates as is done by method 2) and 3).

Word count abstract: 272 
medRxiv preprint doi: https://doi.org/10.1101/2021.11.25.21266868; this version posted November 26, 2021. The copyright holder for this preprint (which was not certified by peer review) is the author/funder, who has granted medRxiv a license to display the preprint in

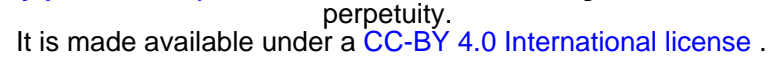

\section{Introduction}

The increasing proportion of people suffering from chronic diseases is peculiarly worrying as these conditions constrain activities of daily living, necessitate ongoing medical attention and hence, are associated with considerably higher costs and healthcare expenses [1]. Disease management activities have been shown to reduce the risk of acute complications and premature mortality caused by chronic diseases [2]. Though, effective responses require accurate estimates of current and future chronic disease burden to tailor health care planning and resource allocation [3]. Worldwide, diabetes mellitus is one of the most frequent chronic diseases, and thus, is a disease with high public health relevance $[1,2,4]$. Current type 2 diabetes (T2D) prevalence is estimated with $7.4 \%$ among men and $7.0 \%$ among women in Germany aged 40 years or older [4,5]. Besides severe late complications, diabetes mellitus leads to significantly higher mortality and is associated with 1.5 to 4.4 times higher health-care costs compared to people without diabetes [1].

Projection models are powerful tools to estimate future case numbers of a disease in order to inform decision-makers and cost-bearers in the health care system. Consequently, further developing and spreading the knowledge about accurate projection methods is essential to counteract the everworsening disease situation. However, different models may vary in their outcomes and closeness to reality [6]. Nonetheless, to our best knowledge, there is no scientific work that systematically compares these different projections methods for the context of chronic diseases. Therefore, the aim of this work is to fill this gap and to introduce, describe, and critically discuss each of the methods individually and in comparison.

In general, projection methods are limited by the availability of epidemiological and demographic data. Consequently, it is common to project and compare several scenarios that reflect on possible future trends in these areas $[3,4,6-8]$. Besides, the choice of the method can considerably affect projection results. In the context of chronic diseases, there are several methodological approaches that have been advocated for case number projections. For example, most reports are based on a 'status quo approach' [6] which relies on a simple application of the current prevalence to population projections. This procedure has been used for instance in the contexts of pulmonology [9], Parkinson's disease [10] and diabetes [11] among others. Probably due to its simplicity, this method is most popular in projection contexts. However, approaches that aim to incorporate for example underlying diseasespecific transition rates, i.e., incidence and mortality, seem more appropriate as they better capture the complex nature of chronic diseases [12]. Therefore, some studies rely on multistate models that incorporate and relate disease-specific transition rates. In this regard, multistate models are widely used in infectious and chronic disease epidemiology [13-15]. For example, Milan and Fetzer [6], Brinks et al. $[8,16]$ and Waldeyer et al. [3] used time-discrete Markov models in the context of dementia, lupus and diabetes. Another approach is used by Carstensen et al. [7] who used a Poisson regression to model disease-specific transition rates of diabetes. Thereof, they extrapolate the future trends of the rates by extending the trends observed in the past. A relatively novel approach is reported by Tönnies et al. [4], who use a partial differential equation to project future diabetes prevalence in Germany. There remains, however, considerable debate about the methodological approach.

In the present article, we give an overview of possible methods and underlying data used for future case number projections in the context of chronic conditions. For this purpose, we will examine three projection methods in more detail. We discuss how to employ each of the approaches in a practical application to project sex- and age-specific case numbers of people with diagnosed T2D for Germany between 2010 and 2040. 
medRxiv preprint doi: https://doi.org/10.1101/2021.11.25.21266868; this version posted November 26,2021 . The copyright holder for this preprint (which was not certified by peer review) is the author/funder, who has granted medRxiv a license to display the preprint in

It is made available under a CC-BY 4.0 International license .

\section{Methods}

In the following section, we describe different models for projecting chronic disease case numbers. All methods were implemented using the free software R, v.4.1.0 (The R Foundation for Statistical Computing).

We focus on three different approaches to project chronic disease case numbers. Previous studies have mostly used a very simple approach, commonly referred to as status quo method [6]. Due to its popularity, we include this procedure in our work, speaking of it as method 1). This approach solely relies on the age- and sex-specific prevalence from a base year, which is then applied to population projections. Other epidemiological factors, such as the incidence, are only incorporated implicitly in the prevalence. Thus, this method ignores the fact that prevalence is a consequence of incidence and mortality. Hence, it might be too simplistic to accurately mirror reality. The alternative methods 2) and 3) rely on demographic components as well as on various disease-specific information on prevalence, incidence, and mortality rates as input factors. Method 2) is aligned with the work of Tönnies et al. [4], who takes advantages of the theory of multistate models in chronic disease epidemiology and an associated partial differential equation (PDE). With method 3) we present a novel projection method, which consists of a two-dimensional system of PDEs. The theoretical background for the PDEs used with method 2) and 3) originates in the illness-death model (IDM) as depicted in Fig 1. The IDM is a multistate model that represents continuous-time stochastic processes. Thereby, it allows individuals to move between a finite number of states $[17,18]$. The classical IDM consists of three states, i.e., "healthy" (number of healthy people aged $a$ at time $t H(t, a)$ ) with regards to the disease of interest, the disease state "ill" (number of ill people $I(t, a)$ ) and the death state, i.e., "dead" $(D)$. It is assumed that at birth all individuals start in the healthy state. From there on, they can either be diagnosed with a chronic disease like T2D and then die at some point in time, or they can transition directly to death state (without contracting diabetes). The arrows indicate the transition rates between the states which depend on age and time. Since diabetes is a chronic condition, we assume that there is no remission from the chronic condition back to the healthy state. The transition rates are given by the incidence rate $I R(t, a)$ the mortality of the non-diseased $m_{0}(t, a)$ and the mortality of diseased people $m_{1}(t, a)$, which are all sex-specific functions of calendar time $t$ and age $a$. In epidemiological contexts, calendar time $t$ is also denoted by period.

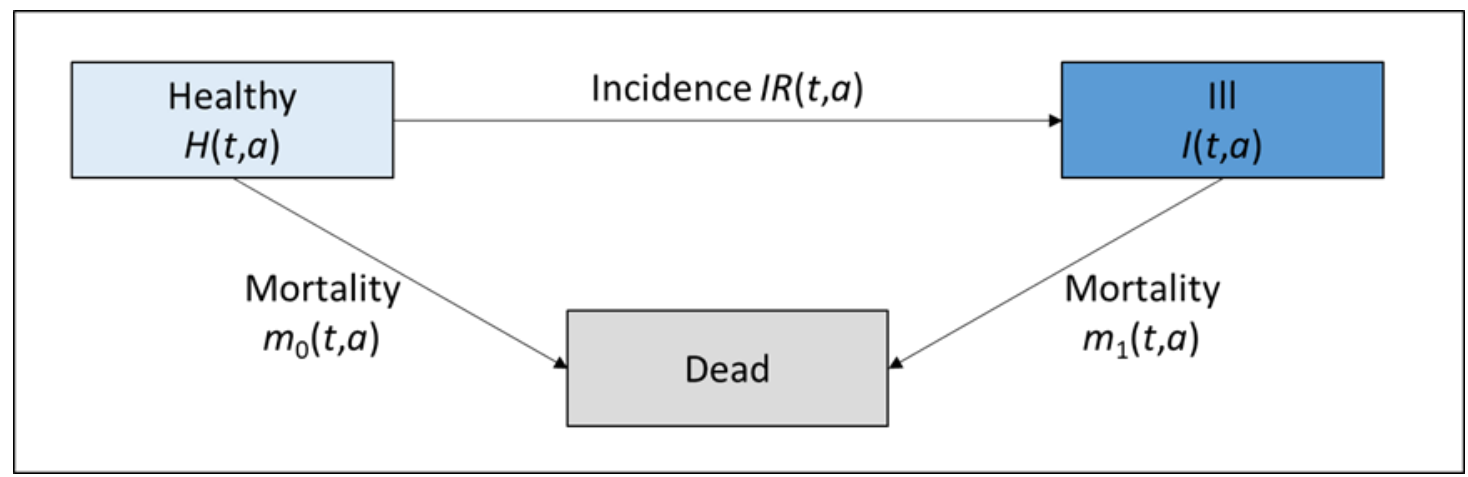

Fig 1. Illness-death model. All people in a population are in one of the three states: Healthy, Diseased, or Dead. It is assumed that at birth, all people start in the healthy state. Depending on time $t$ and age a of each respective person, they will then transition to another state which is described by the rates $I R, m_{0}$, and $m_{1}$. 
medRxiv preprint doi: https://doi.org/10.1101/2021.11.25.21266868; this version posted November 26, 2021. The copyright holder for this preprint (which was not certified by peer review) is the author/funder, who has granted medRxiv a license to display the preprint in

perpetuity.
It is made available under a CC-BY 4.0 International license.

The following sections describe each of the three methods as sketched in Fig 2 and the required input data in more detail. Aggregated data about prevalence and incidence of the chronic condition of interest, as well as on the mortality of the general population and the excess mortality are sufficient, i.e., none of the methods require individual subject data.

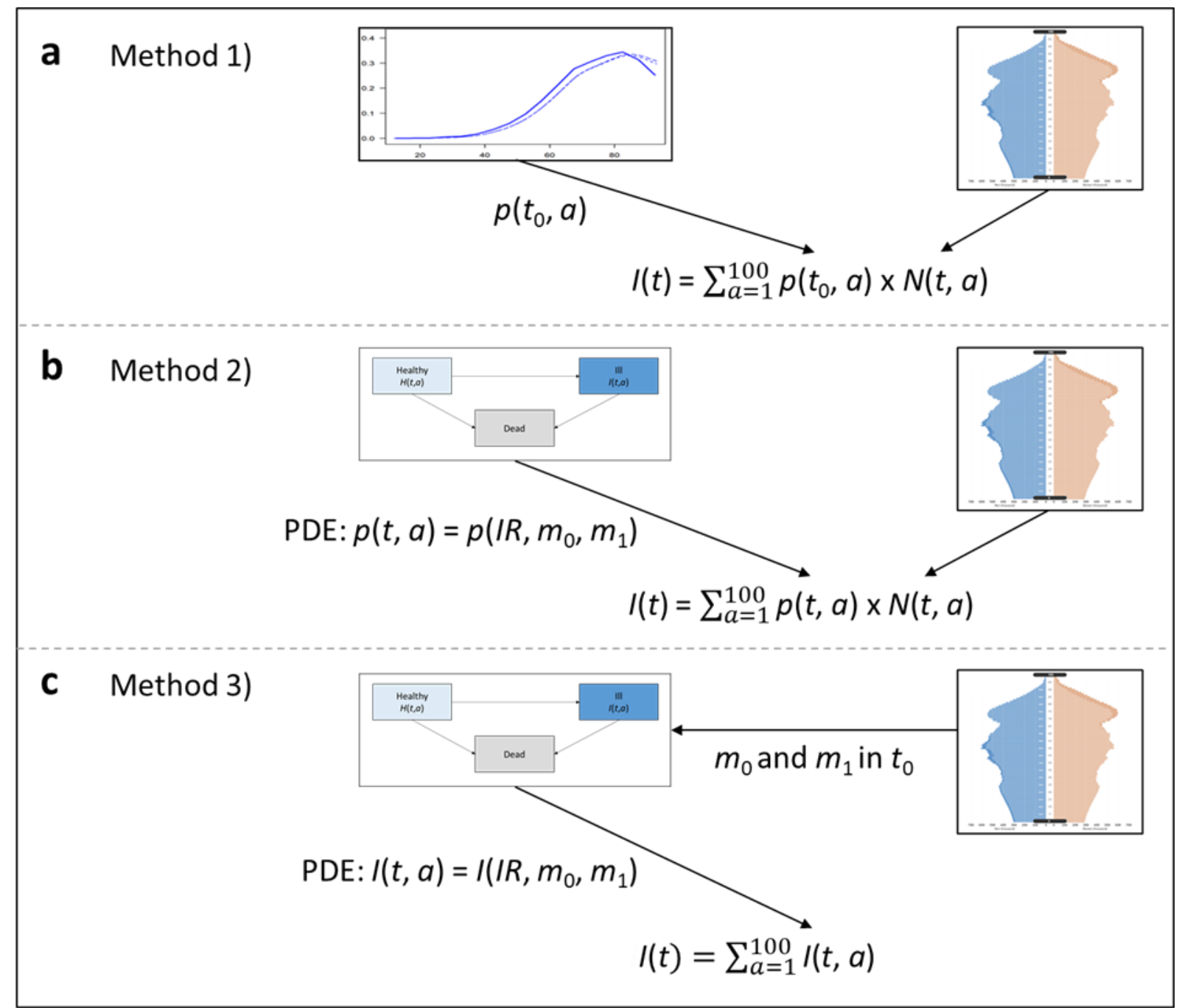

Fig 2. Overview of Methods for Future Disease Case Projection. Illustrated in Fig 2a, method 1) uses the age-specific prevalence in base year to which is applied to the population projections. Fig $2 b$ depicts method 2). Using the theoretical background of the IDM, the age-specific prevalence for each year is derived by solving the PDE which requires input on the transition rates, namely the $I R, m_{0}$ and $m_{1}$. Method 3), as sketched in Fig 2c, calibrates $m_{0}$ and $m_{1}$ in the base year $t_{0}$ from the population projections. IR, $m_{0}$ and $m_{1}$ are inputs for the PDE which directly returns age-specific T2D case numbers for each year. Summing over all ages yields the total number of T2D cases for each year from 2010 to 2040 for each method.

\section{Data}

The starting point for the projections are disease-specific as well as demographic input factors. The required demographic information essentially comprises the expected age and sex-specific population distribution in Germany for each year that is to be included in the projection. The disease-specific input factors include the age- and sex-specific prevalence, incidence rate, and mortality rates of the diseased 
medRxiv preprint doi: https://doi.org/10.1101/2021.11.25.21266868; this version posted November 26,2021 . The copyright holder for this preprint (which was not certified by peer review) is the author/funder, who has granted medRxiv a license to display the preprint in

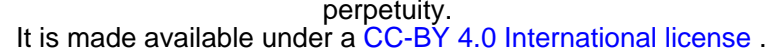

and non-diseased along with information on the age- and sex-specific excess mortality (mortality rate ratio, MRR).

We used published claims data on prevalence and incidence of diagnosed diabetes in 2009 and 2010 from 65 million people insured by the German public health insurance funds [19]. Diabetes was determined by the International Classification of Diseases-10 codes E10-E14. Overall, approximately $10.1 \%$ had any type of diabetes mellitus (excluding gestational diabetes), while $7.3 \%$ were diagnosed with T2D in 2010.

Concerning the population distribution, we used data from the German Federal Statistical Office (FSO) [20] that regularly issues updated projections of future population numbers in Germany. These projections include different scenarios regarding expected birth rate, life expectancy and migration. All projection scenarios contain sex-specific results for all ages from 0 to 100 years for the time horizon between 2010 and 2040. In our main analysis, we focus on one selected variant rather than considering the more extreme ones. Similar to Tönnies et al. [4], we use variant B1L2M1. This variant assumes a birth rate (B) of 1.4 children per woman, a life expectancy (L) at birth in 2040 of 86.7 years for men and a long-term net migration (M) of 100,000 people.

Further, we obtain input values for the mortality rate of the general German population between 2010 and 2040 from the population projections of the German FSO [20]. Distinct information on the mortality rate of the healthy, i.e., non-diseased with regard to T2D, and for the mortality rate of the diseased would be of interest, but unfortunately, the mortality of the healthy population in Germany with respect to T2D is unknown. To cope with this lack of data, we substitute the missing mortality rates for method 2) with a mathematically equivalent expression based on the general mortality and the MRR as an alternative epidemiological measure. For method 3), we show how to calculate the mortality rates of the diseased and the healthy population.

The MRR is based on a similar, nationally representative dataset from 2014 reported by Schmidt et al. [2]. Unfortunately, the MRR is not differentiated by diabetes type. However, since T1D is frequent at ages younger than 20 and T2D is more common among older ages, the MRR is mostly driven by deaths among the latter. Moreover, most diabetes cases are attributable to T2D. Therefore, we use the MRR estimates provided by Schmidt et al. [2] as an approximation of the T2D-related MRR in Germany.

Further, reliable information on the temporal trend of the diabetes-specific MRR is relatively restricted in Germany. Following the work of Brinks et al. [8] and Tönnies et al. [4], we therefore refer to trends in the sex- and age-specific MRR observed in Denmark [21]. The motivation to do so is twofold. Firstly, it has been shown that for countries that are comparable in terms of their disease burden and health care systems, such as Denmark and Germany, the MRR settles in a similar range [22]. More precisely, a $2 \%$ decrease in the MRR per year is reported for Denmark [21]. Secondly, the same approach is used by Tönnies et al. [4], who also assume a decrease of $2 \%$ per year in the MRR as observed in other countries.

\section{Method 1 - the simple approach}

Method 1) combines diabetes prevalence with population projections as depicted in Fig 2a. Specifically, to project the number of T2D cases until 2040, we multiplied German age- and sex-specific population projections provided by the FSO with age- and sex-specific T2D prevalence in 2010 from Tamayo et al. [23]. The latter is assumed to remain constant. The age- and sex-specific prevalence in 2010, $p(t, a)$ is determined by:

$$
p(2010, a)=\frac{I(2010, a)}{H(2010, a)+I(2010, a)}
$$


medRxiv preprint doi: https://doi.org/10.1101/2021.11.25.21266868; this version posted November 26, 2021. The copyright holder for this preprint (which was not certified by peer review) is the author/funder, who has granted medRxiv a license to display the preprint in

perpetuity.
It is made available under a CC-BY 4.0 International license .

with $/(2010, a)$ being the number of people diagnosed with T2D in 2010 and $H(2010, a)$ the number of people without T2D in 2010. The underlying mathematical relation to calculate the age- and sexspecific future number of cases $I(t, a)$ is then given by:

$$
I(t, a)=N(t, a) \times p(2010, a)
$$

where $N(t, a)$ denotes the age-, sex- and time-dependent total population number and $p(2010, a)$ the age-specific prevalence in the year 2010.

\section{Method 2 - the two-step multistate model}

Method 2) refines the first method. To this end, we use mathematical relations to incorporate the relation between prevalence, incidence, and mortality, as well as temporal changes in the incidence and mortality [24]. More precisely, with method 2) we firstly model the temporal change in prevalence of T2D employing a PDE [25]. Secondly, we compute future T2D case numbers by multiplying the ageand sex-specific projected prevalence with the respective projected population size (Fig $2 \mathrm{~b}$ ).

Brinks et al. [26] showed that the change in prevalence can be modelled by a PDE in case information about mortality, incidence and prevalence at a specific time point is given. The PDE is given by

$$
\partial p=(1-p) \times\left[I R-p \times\left(m_{1}-m_{0}\right)\right]
$$

In other words, method 2 ) relies on the relation between prevalence $p(t, a)$, the incidence rate $I R(t, a)$ and the mortality rates $m_{0}(t, a)$ and $m_{1}(t, a)$. Unfortunately, $m_{0}(t, a)$ is unknown for most diseases. Therefore, we use $m(t, a)$ the mortality of the general population, and the age- and sex-specific $M R R(t$, a) which denotes the ratio of the two mortality rates, i.e. $\frac{m_{1}(t, a)}{m_{0}(t, a)}$. The general mortality is defined as

$$
m=p \times m_{1}+(1-p) m_{0}
$$

The PDE can then be rewritten as

$$
\partial p=(1-p) \times\left[I R-\frac{p \times(M R R-1) \times m}{p \times(M R R-1)+1}\right]
$$

For the present application to the context of T2D, this allows us to project the change in prevalence at a certain age and time even without data about $m_{0}(t, a)$. Accordingly, we integrate the PDE using input values for the projected general mortality of the German population as provided by the FSO. Recall that the equation is particularly favourable since the PDE allows for incorporating temporal trends in the IR and MRR. In a final step, the estimated prevalence $p(t, a)$ is multiplied with the population projections of the FSO [20] as follows

$$
I=N \times \hat{p}
$$


medRxiv preprint doi: https://doi.org/10.1101/2021.11.25.21266868; this version posted November 26, 2021. The copyright holder for this preprint (which was not certified by peer review) is the author/funder, who has granted medRxiv a license to display the preprint in

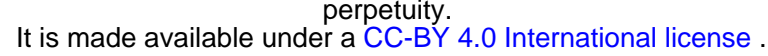

This yields case numbers of T2D in Germany $I(t, a)$ for each year between 2010 and 2040 for all ages ranging from 18 to 100 years. All ages below 18 years were considered negligible due to minimal prevalence at these ages [4,23].

\section{Method 3 - the two-dimensional PDE model}

Similar to method 2), the third method builds upon the IDM. Though, method 3) features two PDEs as sketched in Fig $2 \mathrm{c}$ to directly express changes in the age- and sex-specific numbers of diabetes cases, i.e., $I(t, a)$, and the changes in the healthy population $H(t, a)$. We can show that these two figures $I(t$, $a)$ and $H(t, a)$ are interrelated with the transition rates $I R(t, a), m_{0}(t, a)$ and $m_{1}(t, a)$ via the following equations

$$
\begin{gathered}
\partial H=-\left(I R+m_{0}\right) \times H \\
\partial I=I R \times H-m_{1} \times I
\end{gathered}
$$

$\partial H(t, a)$ indicates age-, sex- and time-specific changes in the number of people without diabetes, while $\partial I(t, a)$ represents changes in the number of cases. As $m_{0}(t, a)$ is unknown for Germany, we use the T2D prevalence from 2010, the general mortality $m(t, a)$ and the $\operatorname{MRR}(2014, a)$ to derive values for $m_{0}(t, a)$ and $m_{1}(t, a)[21,22,27]$. Precisely, $m_{0}(t, a)$ and $m_{1}(t, a)$ are calculated by

$$
\begin{gathered}
m_{0}=\frac{m}{(1+p \times(M R R-1))} \\
m_{1}=m_{0} \times M R R
\end{gathered}
$$

In contrast to method 2), we only need data on the general mortality and MRR in 2010 for method 3) which is then used to determine $m_{0}(t, a)$ and $m_{1}(t, a)$. Besides, we derive information on the development of the future birth rate of the population projections. However, using only information on the annual number of new-borns is little critical for our projection period, as the projection ends in 2040. That means, someone born in 2020 will then be 20 years old and will thus not belong to the diabetes risk group. That means we do not need further information from population projections that are based on historical data and thus subject to retrograde developments as provided by the FSO [20]. This is favourable as these population projections do not explicitly take specific diseases into account. In contrast, using method 3) and a two-dimensional system of PDEs allows us to reflect on short-term changes especially with regards to relevant disease-specific alterations. As outcome, the PDEs directly describe the age- and sex-specific number of people with and without T2D for each year between 2010 and 2040.

\section{Sensitivity analysis}

In sensitivity analyses, we assessed uncertainty due to sampling error of the input values as well as uncertainty due to unknown future trends in the model parameters. In order to inspect uncertainty that could arise due to sampling error of the input values, we perform a Monte Carlo simulation for all three methods. To evaluate the latter, i.e., uncertainty due to future trends, we analyse 14 different scenarios of declining or rising MRR and IR with methods 2) and 3) following the example of Tönnies et al. [4]. 
medRxiv preprint doi: https://doi.org/10.1101/2021.11.25.21266868; this version posted November 26, 2021. The copyright holder for this preprint (which was not certified by peer review) is the author/funder, who has granted medRxiv a license to display the preprint in

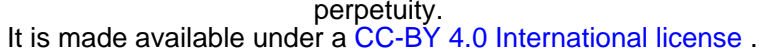

\section{Results}

Based on the age-specific prevalence in 2010, we projected the age-specific case numbers for T2D in the German male population between 2010 and 2040 using the above-mentioned approaches. Remember that we assume a constant age-specific prevalence with method 1), i.e., we apply the prevalence from 2010 to our population projections. We further assumed that also the IR remains constant over time for method 2) and 3) in the main analysis. However, we consider temporal trends in the MRR for method 2) and 3) which affects, amongst others, the prevalence. Since for Germany, information on long-term trends in the latter are limited, we use speculative time-related developments. Current evidence undermines that the mortality rate among people with T2D is likely to decrease faster than among healthy people due to progresses in medical care [21]. Therefore, it seems plausible to assume a reduction in the MRR 28. For simplicity, we restrict the main analysis to a baseline scenario for method 2) and 3) which thus comprises a constant IR and a decrease in the MRR of $2 \%$ per year. We reflect on rather likely, as well as on relatively extreme scenarios for the MRR and IR in the sensitivity analyses discussed in the supporting information.

Fig 3 depicts the number of projected male T2D cases in Germany between 2010 and 2040 using the three different approaches. All the proposed methods suggest that the number of people with diabetes continues to grow in Germany. However, the projected number of male T2D cases differs substantially across the three methods. It is clearly visible that over time the difference between the projected values from each of the three methods enlarges. Since only the population composition changes over time, method 1 ) shows only slightly increasing future case numbers. In contrast, methods 2) and 3) also take into account the incidence and mortality, which influence the prevalence and number of cases. This, in addition to the demographic aging, is above all the reason for the higher number of projected T2D cases for these methods compared to method 1 ). 


\section{Projected Male Type 2 Diabetes Cases in Germany}

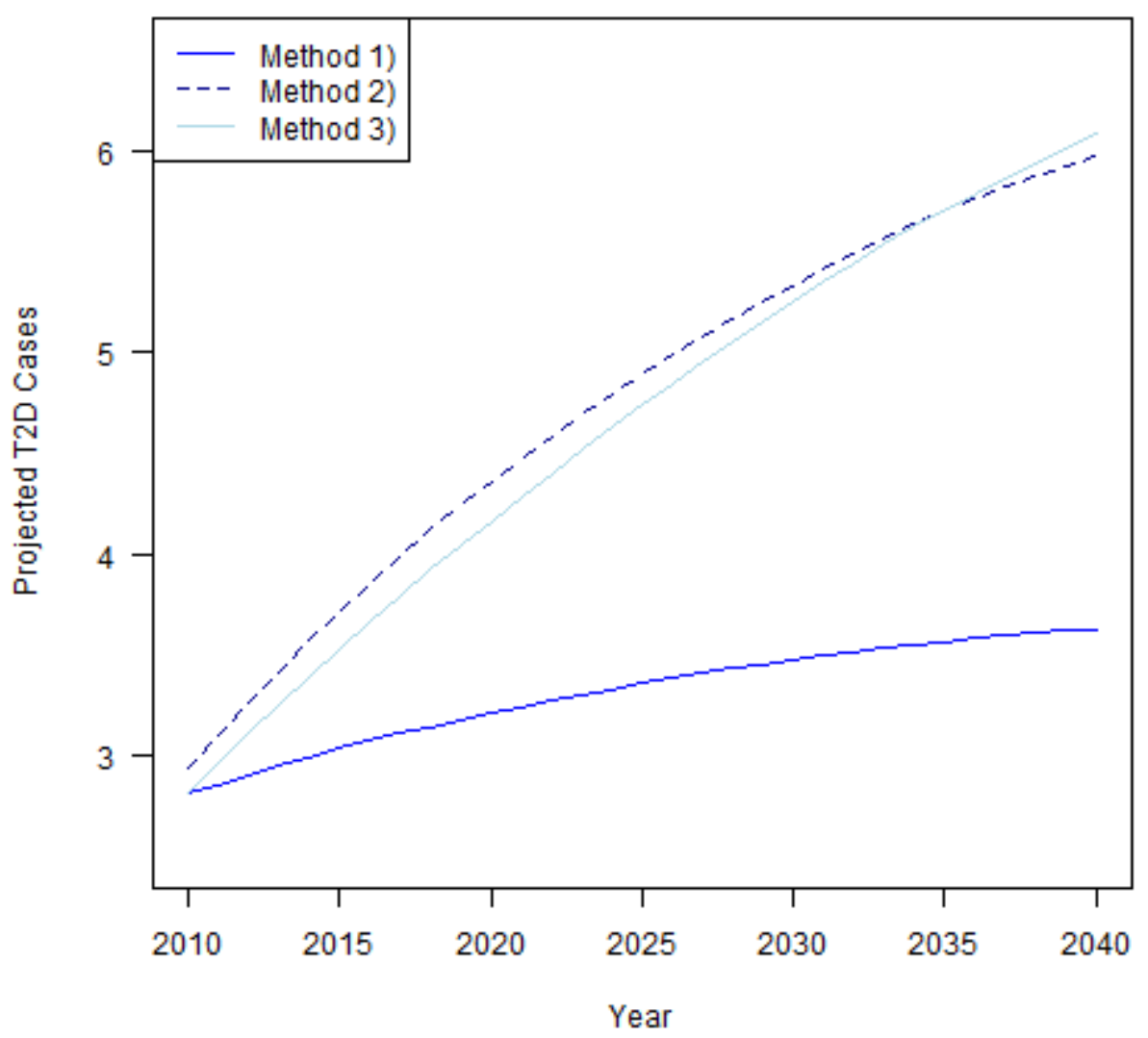

Fig 3. T2D case projection results. Projected male T2D cases in Germany for variant B1L2M1 of the population projections of the German FSO between 2010 and 2040. The population projection variant is based on constant birth rates, increases in life expectancy and a net migration of 100000 people. Method 1) assumes constant age-specific prevalence, method 2) and method 3) build on constant incidence rate and $2 \%$-decrease in the MRR.

Table 1 displays the projected T2D case numbers among men in Germany in millions and the relative changes from 2010 compared to 2040 in percent. With method 1), we find an increase of male T2D case numbers by 0.8 million. This equals a total of almost 3.6 million T2D cases among males in Germany in 2040 ( $+29 \%$ ). When presuming that the MRR decreases by $2 \%$ per year while the IR is assumed to remain constant, the number of cases is projected to increase by about 3.0 million ( $+104 \%)$ and 3.3 million ( $+116 \%$ ) for method 2 ) and method 3 ), respectively. Apparently, the results show an obvious gap between method 1) and the other two methods. Interestingly, the difference between the projected case numbers of the latter methods is minor: During the entire time horizon of the projection until 2035, the future number of T2D cases for method 2) is slightly higher than the number projected by method 3). Thereafter, method 3) projects a higher number of male T2D cases in Germany.

Table 1: T2D case projection results (in Million).

\begin{tabular}{|l|l|l|l|l|r|r|r|}
\hline Method & 2010 & 2020 & 2030 & 2040 & $\begin{array}{l}\text { Absolute } \\
\text { difference }\end{array}$ & $\begin{array}{l}\text { Relative } \\
\text { difference }\end{array}$ \\
\hline 1$)$ & 2.81 & 3.21 & 3.47 & 3.63 & 0.82 & $29.09 \%$ \\
\hline
\end{tabular}


medRxiv preprint doi: https://doi.org/10.1101/2021.11.25.21266868; this version posted November 26,2021 . The copyright holder for this preprint (which was not certified by peer review) is the author/funder, who has granted medRxiv a license to display the preprint in

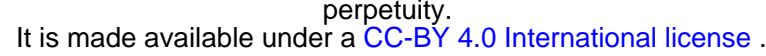

\begin{tabular}{|l|r|r|r|r|r|r|}
\hline 2) & 2.93 & 4.36 & 5.33 & 5.97 & 3.04 & $103.60 \%$ \\
\hline 3$)$ & 2.81 & 4.16 & 5.25 & 6.08 & 3.27 & $116.34 \%$ \\
\hline
\end{tabular}

Results are based on variant B1L2M1 of the German FSO (absolute (in Million) and relative (in percent) difference with regards to 2010 vs. 2040).

S1 and S2 Fig refer to the age-specific prevalence among males in Germany from 2010 to 2040 projected using the different methods. We find apparent discrepancies in the age-specific prevalence for the methods. Compared to the constant prevalence assumed by method 1), the prevalence computed with methods 2 ) and 3 ) is expected to increase considerably, particularly for people older than 60 years. Additionally, the peak prevalence is presumed to shift towards older age groups. We provide further details in the supporting information.

\section{Sensitivity analyses}

We performed several sensitivity analyses to assess inaccuracies and uncertainty in our results which we briefly discuss in this section. More detailed information on results and computation is given in the supplementary information.

General future epidemiological trends for the age-specific IR or the MRR are heterogeneous and precise information are not available for Germany [4,5]. Therefore, we considered 14 different scenarios of declining or rising MRR and IR and examined the impact on future case numbers using method 2) and 3). We find considerably large deviations in the number of projected T2D cases: With the most extreme scenarios we project a decrease of approx. 0.3 million (-11\%; stable MRR \& IR $-5 \%)$ or an increase of 6.3 million (216\%; MRR -2\% \& IR +3\%) male T2D cases between 2010 and 2040 for Germany ( $\mathrm{S} 3 \mathrm{Fig}$ ). This is an essential finding, as it underlines how impactful disease-specific factors are in projection contexts. This result is strongly in favour of method 2) and 3), as these approaches incorporate the rates underlying the prevalence in the mathematical model.

In order to assess uncertainty in our results, we calculated $95 \%$ confidence intervals using a Monte Carlo simulation as shown in S4 Fig. The sampling error of the input values led to deviations in the future number of cases by approximately $7.2 \%$ for method 2 ) and by about $3.5 \%$ for method 3 ). Hence, the Monte Carlo simulation shows that the uncertainty due to sampling error in the input values seems to be of limited relevance. We report further information about the calculation and the estimation results in the supporting information.

\section{Discussion}

The aim of this article is to assess and advance the usage and performance of different projection methods in chronic disease modelling. While there is a lack thereof in previous publications, we compared the underlying assumptions, mathematical details, strengths, and limitations of three distinct projection methods and demonstrated their usage. Precisely, in this article, we discussed three methods to project age- and sex-specific case numbers of a chronic condition from age- and sexspecific prevalence, incidence, and mortality data. Further, we illustrated each method in a practical application in the context of T2D among males in Germany for the time period from 2010 to 2040. We found considerable differences between the results of the three methods.

Generally, all three methods can be easily adapted to other chronic diseases or countries. Additionally, for Germany, data about the future population number is available until 2060, i.e., the projection of T2D case numbers can be extended easily to the far-off future. Nonetheless, a projection is subject to 
medRxiv preprint doi: https://doi.org/10.1101/2021.11.25.21266868; this version posted November 26, 2021. The copyright holder for this preprint (which was not certified by peer review) is the author/funder, who has granted medRxiv a license to display the preprint in

perpetuity.
It is made available under a CC-BY 4.0 International license .

some unforeseen changes in the economic, political, or disease-specific environment amongst others. Generally, the reliability of projections decreases over time. Therefore, instead of delving further into the future and thereby decreasing certainty, we restricted the projection until 2040.

In many previous projections on chronic diseases, age- and sex-specific prevalence from a base year is transferred to population projections as in method 1) [6,9-11]. Population projections required for this purpose, generated using the so-called cohort component method $[6,29]$, are widely used and publicly available in Germany. For the calculation, the birth cohorts are hypothetically extrapolated from a base year under assumptions on the future development of fertility, mortality, and net migration. But just as the future population depends on several components, the development of a disease is also influenced by various disease-specific aspects [6]. However, the latter are ignored in method 1). Methods 2) and 3) include disease-specific information on mortality, prevalence, and incidence rates as input factors in addition to the demographic components mentioned above. Thus, as opposed to method 1), the PDEs used in method 2) and 3) account for temporal trends in the prevailing epidemiological situation. To do so, aggregated data are sufficient. Method 2) incorporates the MRR and IR, as opposed to solely using the prevalence as is done by method 1). Though, method 2 ) is, as method 1), still based on projections of the population and the general mortality in Germany. The future estimates of the German FSO do not consider potential epidemiological influences and simply extrapolate future values based on long-term trends of the past [20]. Contrarily, using method 3), we can take short-term fluctuations in the mortality into account. The results of method 3) are independent from projections of the German FSO beyond the year used to estimate $m_{0}$ and $m_{1}$. Instead, this method purely relies on input values on the age- and sex-specific prevalence, the MRR and the general mortality for a base year. The latter are used to estimate the mortality of the nondiseased and the mortality of diseased people. Furthermore, instead of calculating the prevalence in each year for each age group, method 3) directly returns future changes in absolute case and population numbers.

Lastly, different future scenarios that anticipate potential impacts of alternative scenarios of prevention and intervention or disease-dynamics can be computed and compared using method 2) or 3). The comparison of methods 2 ) and 3) with method 1) reveals the great impact of trends in incidence and mortality on future disease burden. Our findings confirm the suggestion that ignoring temporal trends in incidence and mortality provokes an underestimation of the actual number of cases [4]. Consequently, a future course can be better, if not optimal, approximated using method 2) and 3).

\section{Limitations}

A primary limitation for method 2) and 3) is that they need assumptions about the temporal changes in the IR and MRR. Unfortunately, information about future trends in Germany in the context of T2D is scarce. Therefore, we made assumptions about future trends of the IR and MRR that may be oversimplified. Further, it is noteworthy that our population projection methods are trend-based, hence, they may be less accurate for instance in periods of sudden and fast changes in the incidence. However, also the intensity, frequency and pace of changes have implications on epidemiologically relevant measures such as the prevalence and the number of cases. As discussed, variant projections, which are feasible with method 2) and 3), can provide additional information by illustrating potential alternative scenarios of future trends. Aside from that, rapid changes in chronic disease incidences are rare and the general impact of high-frequency distortions in future trends is often limited by the inertia in population change. 
medRxiv preprint doi: https://doi.org/10.1101/2021.11.25.21266868; this version posted November 26, 2021. The copyright holder for this preprint (which was not certified by peer review) is the author/funder, who has granted medRxiv a license to display the preprint in It is made available under a CC-BY 4.0 International license .

Another limitation of all three methods arises with a potential violation of the assumption that the prevalence in migrants is equal to the prevalence observed among German residents. Though, the T2D prevalence in people migrating from and to Germany is unknown. However, other examples show that this issue is minor and overall epidemiological measures are only negligibly affected $[4,25]$. Though, one should keep in mind that it may remain an issue e.g., for small populations.

Another weakness of the methods arises with the ignored effect of potential covariates and their development. Examples for relevant covariates in the diabetes context might be a change of diagnostic criteria for T2D, the distribution of body weight, the impact of nutritional behaviour, or the presence of co-morbidities. In an epidemiological context, it may be essential to consider such covariates since they likely modify the transition rates between the states in the IDM. Although this is not done in this work, it is possible to account for the impact of possible covariates such as interventions and riskfactors in the PDEs [30].

\section{Conclusion}

Forecasts of the growing non-communicable disease burden will be key to guide future healthcare policies. With this work, we compare three projection methods and demonstrated how to apply each of them to quantify future T2D case numbers in Germany until 2040. The three methods uniformly confirm that there is a substantial increase in the number of males diagnosed with T2D ranging from 0.8 million (+29\%) to 3.3 million (+116\%) additional cases in Germany in 2040. Assessing the strengths and limitations of three different methods may help researchers to better apply statistical methods for projecting future case numbers of chronic diseases. We suggest that future projections should move away from blunt prevalence extrapolation and instead, employ methods that are based on theory from the IDM. 
medRxiv preprint doi: https://doi.org/10.1101/2021.11.25.21266868; this version posted November 26, 2021. The copyright holder for this preprint (which was not certified by peer review) is the author/funder, who has granted medRxiv a license to display the preprint in

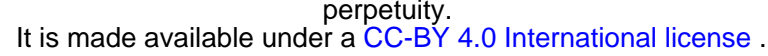

\section{References}

[1] Jacobs E, Hoyer A, Brinks R, Icks A, Kuß O, Rathmann W. Healthcare costs of type 2 diabetes in Germany. Diabet Med 2017;34(6):855-61.

[2] Schmidt C, Reitzle L, Heidemann C, Paprott R, Ziese T, Scheidt-Nave C, et al. Excess mortality in adults with documented diabetes in Germany: routine data analysis of all insurance claims in Germany 2013-2014. BMJ Open 2021;11(1):1-8.

[3] Waldeyer R, Brinks R, Rathmann W, Giani G, Icks A. Projection of the burden of type 2 diabetes mellitus in Germany: a demographic modelling approach to estimate the direct medical excess costs from 2010 to 2040. Diabet Med 2013;30(8):999-1008.

[4] Tönnies T, Röckl S, Hoyer A, Heidemann C, Baumert J, Du Y, et al. Projected number of people with diagnosed Type 2 diabetes in Germany in 2040. Diabet Med 2019;36(10):1217-25.

[5] Goffrier B, Schulz M, Bätzing-Feigenbaum J. Administrative Prävalenzen und Inzidenzen des Diabetes mellitus von 2009 bis 2015: Versorgungsatlas-Bericht. Zentralinstitut für die kassenärztliche Versorgung in Deutschland (Zi) 2017(17):1-34.

[6] Milan V, Fetzer S. Die zukünftige Entwicklung von Demenzerkrankungen in Deutschland - ein Vergleich unterschiedlicher Prognosemodelle. Bundesgesundheitsblatt Gesundheitsforschung Gesundheitsschutz 2019;62(8):993-1003.

[7] Carstensen B, Rønn PF, Jørgensen ME. Components of diabetes prevalence in Denmark 19962016 and future trends until 2030. BMJ Open Diabetes Res Care 2020;8(1):1-7.

[8] Brinks R, Tamayo T, Kowall B, Rathmann W. Prevalence of type 2 diabetes in Germany in 2040: estimates from an epidemiological model. Eur J Epidemiol 2012;27(10):791-7.

[9] Pritzkuleit R, Beske F, Katalinic A. Erkrankungszahlen in der Pneumologie - eine Projektion bis 2060. Pneumologie 2010;64(9):535-40.

[10] Rossi A, Berger K, Chen H, Leslie D, Mailman RB, Huang X. Projection of the prevalence of Parkinson's disease in the coming decades: Revisited. Mov Disord 2018;33(1):156-9.

[11] Boyle JP, Honeycutt AA, Narayan KV, Hoerger TJ, Geiss LS, Chen H, et al. Projection of diabetes burden through 2050: impact of changing demography and disease prevalence in the U.S. Diabetes Care 2001(24):1936-40.

[12] Carstensen B, Kristensen JK, Ottosen P, Borch-Johnsen K. The Danish National Diabetes Register: trends in incidence, prevalence and mortality. Diabetologia 2008;51(12):2187-96.

[13] Kermack WO, McKendrick AG. A contribution to the mathematical theory of epidemics. Proceedings of the royal society of london 1927(115):700-21.

[14] Fix E, Neyman JA. A simple stochastic model of recovery, relapse, death and loss of patients. Human Biology 1951(23):205-241.

[15] Keiding N. Age-specific incidence and prevalence: a statistical perspective. Royal Statistical Society 1991(154):371-412.

[16] Brinks R, Fischer-Betz R, Sander O, Richter JG, Chehab G, Schneider M. Age-specific prevalence of diagnosed systemic lupus erythematosus in Germany 2002 and projection to 2030. Lupus 2014;23(13):1407-11.

[17] Brinks R. Illness-Death Model in chronic disease epidemiology: characteristics of a related, differential equation and an inverse problem. Comput Math Methods Med 2018;2018:1-6.

[18] Murray CJL, Lopez AD. The global burden of disease. Cambridge: Harvard University Press. 27 p.

[19] Deutsches Institut für Medizinische Dokumentation und Information (DIMDI). Aktuell Informationssystem Versorgungsdaten [Internet] [cited 2015 Aug 11]. Available from: www.dimdi.de/static/de/versorgungsdaten/aktuelles/news_0364.html_319159480.html. 
medRxiv preprint doi: https://doi.org/10.1101/2021.11.25.21266868; this version posted November 26, 2021. The copyright holder for this preprint (which was not certified by peer review) is the author/funder, who has granted medRxiv a license to display the preprint in It is made available under a CC-BY 4.0 International license .

[20] Statistisches Bundesamt. 14. koordinierte Bevölkerungsvorausberechnung [Internet]; 2019 [cited 2021 Oct 30]. Available from: https://wwwgenesis.destatis.de/genesis/online?sequenz=statistikTabellen\&selectionname=12421\#abreadcr umb.

[21] Carstensen B, Rønn PF, Jørgensen ME. Prevalence, incidence and mortality of type 1 and type 2 diabetes in Denmark 1996-2016. BMJ Open Diabetes Res Care 2020;8(1):1-9.

[22] Brinks R, Tönnies T, Hoyer A. Impact of diagnostic accuracy on the estimation of excess mortality from incidence and prevalence: simulation study and application to diabetes in German men. F1000Res 2021;10:1-16.

[23] Tamayo T, Brinks R, Hoyer A, Kuß OS, Rathmann W. The prevalence and incidence of diabetes in Germany. Dtsch Arztebl Int 2016;113(11):177-82.

[24] Kalbfleisch JD, Prentice RL. The statistical analysis of failure time data, Vol 360: John Wiley \& Sons; 2011.

[25] Brinks R, Landwehr S. Age-and time-dependent model of the prevalence of non-communicable diseases and application to dementia in Germany. Theoretical population biology 2014;92:62-8.

[26] Brinks R, Tönnies T, Hoyer A. New ways of estimating excess mortality of chronic diseases from aggregated data: insights from the illness-death model. BMC Public Health 2019;19(1):1-7.

[27] Brinks R, Hoyer A, Weber S, Fischer-Betz R, Sander O, Richter JG, et al. Age-specific and sexspecific incidence of systemic lupus erythematosus: an estimate from cross-sectional claims data of 2.3 million people in the German statutory health insurance 2002. Lupus Sci Med 2016;3(1):13.

[28] Tönnies T, Hoyer A, Brinks R. Productivity-adjusted life years lost due to type 2 diabetes in Germany in 2020 and 2040. Diabetologia 2021;64(6):1288-97.

[29] Whelpton PK. An empirical method of calculating future population. Journal of the American Statistical Association 1936;31(195):457-73.

[30] Hoyer A, Kaufmann S, Brinks R. Risk factors in the illness-death model: Simulation study and the partial differential equation about incidence and prevalence. PLoS One 2019;14(12):1-10. 
medRxiv preprint doi: https://doi.org/10.1101/2021.11.25.21266868; this version posted November 26,2021 . The copyright holder for this preprint (which was not certified by peer review) is the author/funder, who has granted medRxiv a license to display the preprint in

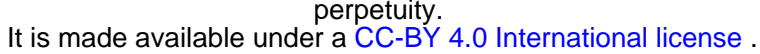

\section{Supporting information}

Additional supporting information may be found online in the supporting information section at the end of the article.

\section{S1 Appendix. R code.}

S1 Fig. Comparing T2D prevalence projections. Projected age-specific prevalence of T2D among males in Germany in 2015, 2020, 2030 and 2040 for method 1), 2) and 3). Projections are based on variant B1L2M1 of the FSO population projections. Method 1) assumes constant age-specific prevalence, method 2) and 3) assume a constant T2D incidence rate but a yearly decrease of $2 \%$ in the MRR.

S2 Fig. Projected prevalence across future population variants. Projected overall prevalence of T2D between 2015 and 2040 in Germany among men for four population projections of the German FSO. Method 1) is based on constant age-specific prevalence; method 2) and 3) assume constant incidence rates and a $2 \%$-decrease in the mortality rate ratio per year. The figure shows similar outcomes for the same method across the different population variants. Though, within the variants, the method's results visibly differ. We infer that the impact of the projection method on the prevalence is larger than the influence of different population projections.

S3 Fig. Projected male T2D cases using different scenarios for the MRR and IR. The 14 different scenarios (grey dashed lines) of the MRR and IR implemented in method 2) cause considerably large deviations in the number of future cases. Some scenarios are rather extreme cases and thus, less likely. Though, it is noteworthy here how susceptible results are to changes in disease-specific input. Blue solid line represents the results of method 1 ) and assuming constant prevalence. Blue dashed line and blue dotted line represent method 2) and 3 ) assuming a constant IR and a decrease of $2 \%$ in the MRR, respectively.

S4 Fig. Projected number of T2D cases in Germany among men between 2015 and 2040. The lightgrey shaded areas show the upper and lower $95 \%$ confidence bounds for method 1). Light-blue dashed lines show the results from our Monte Carlo simulation using method 2) and assuming constant T2D incidence rate and a decreasing MRR. The shaded areas in green represent the confidence intervals for method 3) and assuming constant T2D incidence rate and a decreasing MRR. 


\section{Projected Male Type 2 Diabetes Cases in Germany}

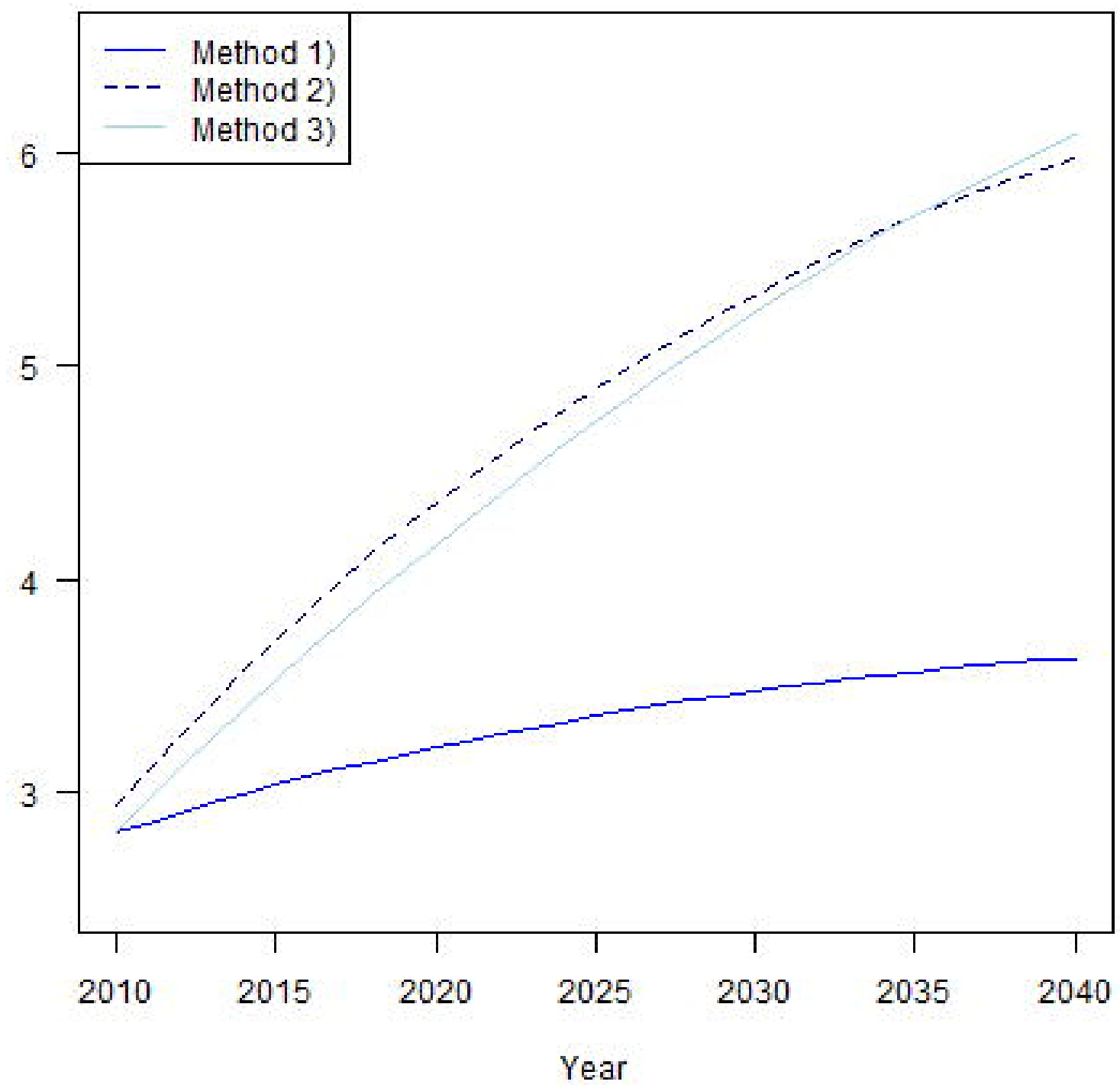




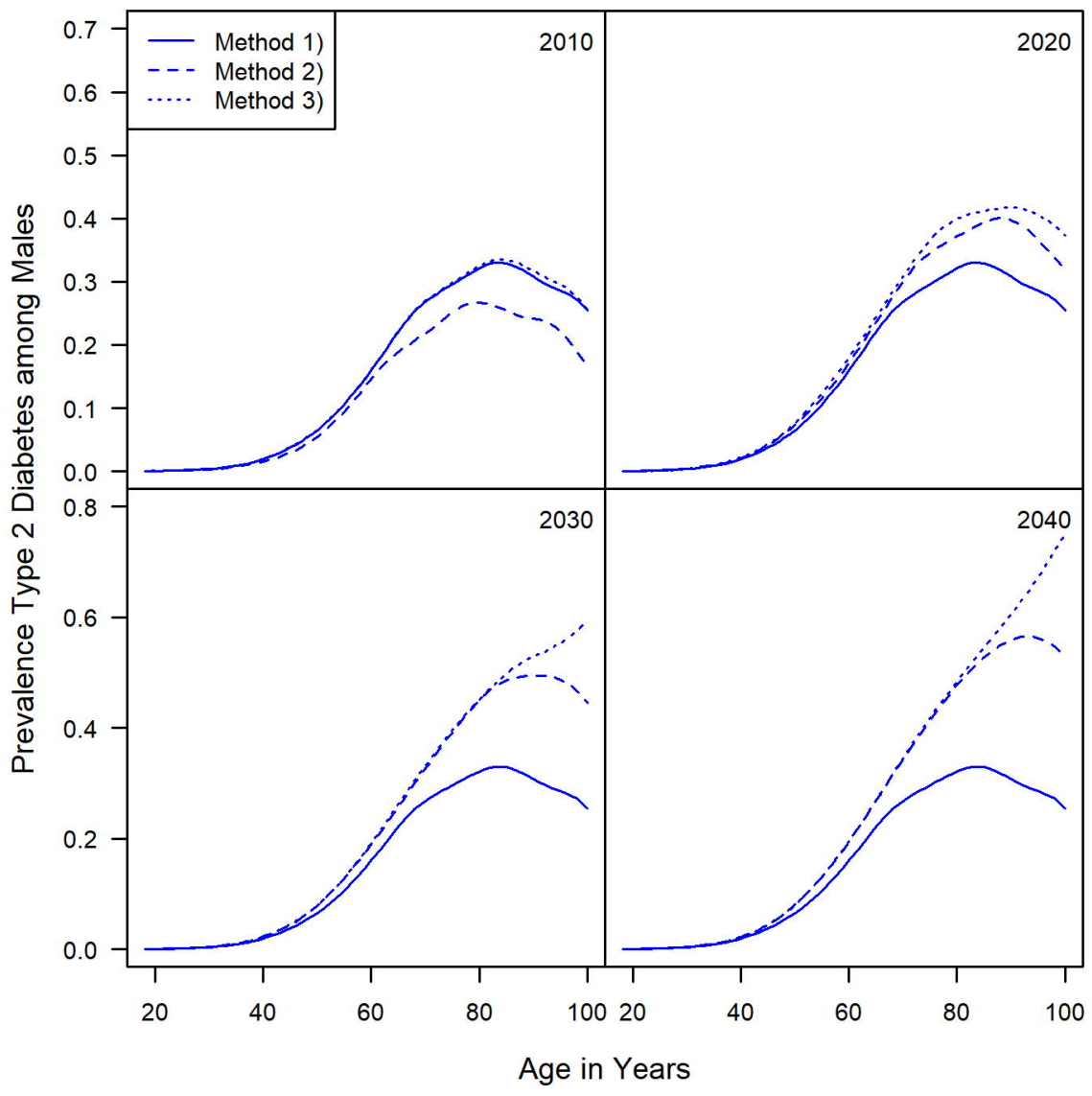









\section{Projected Male Type 2 Diabetes Cases}

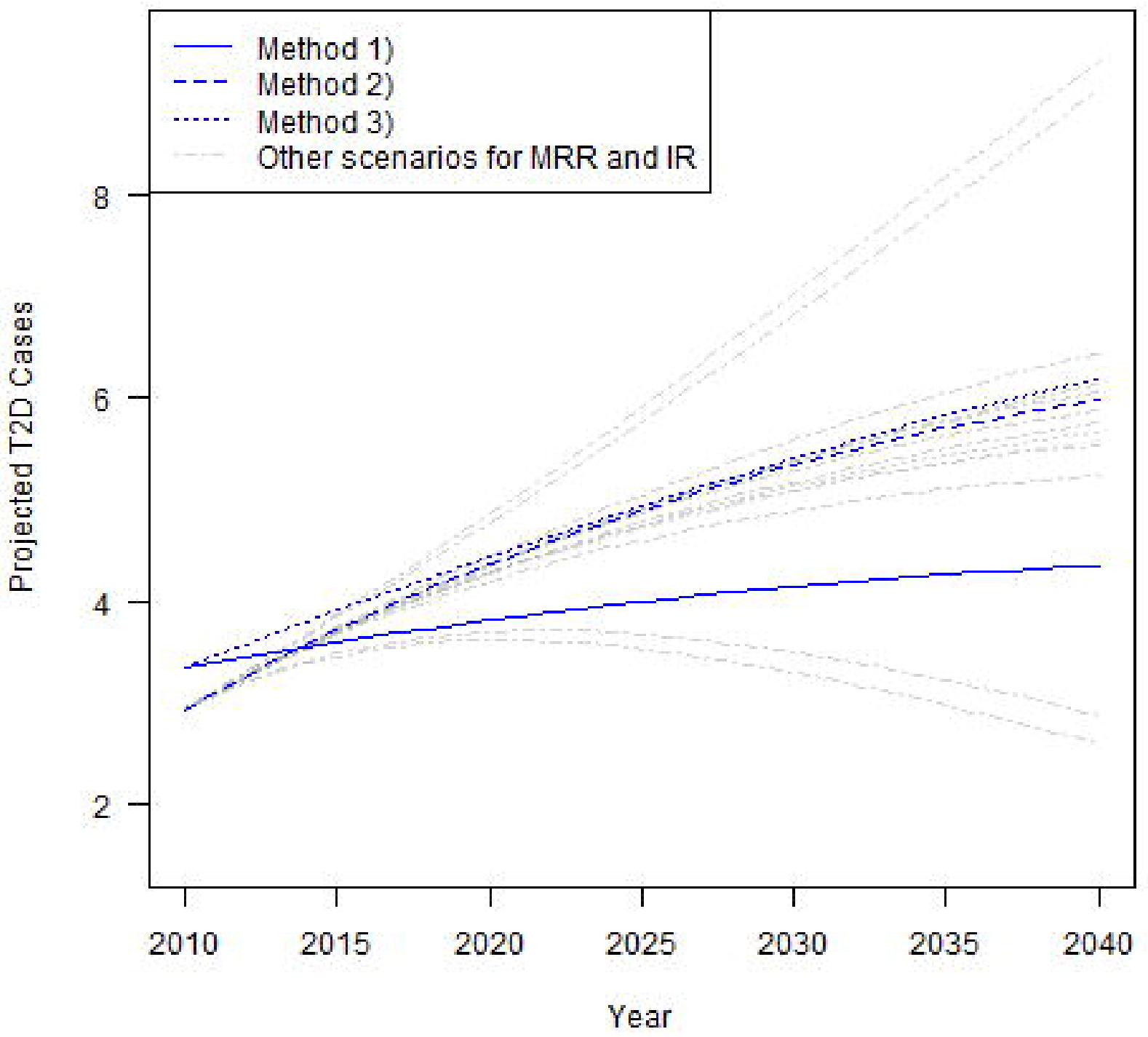




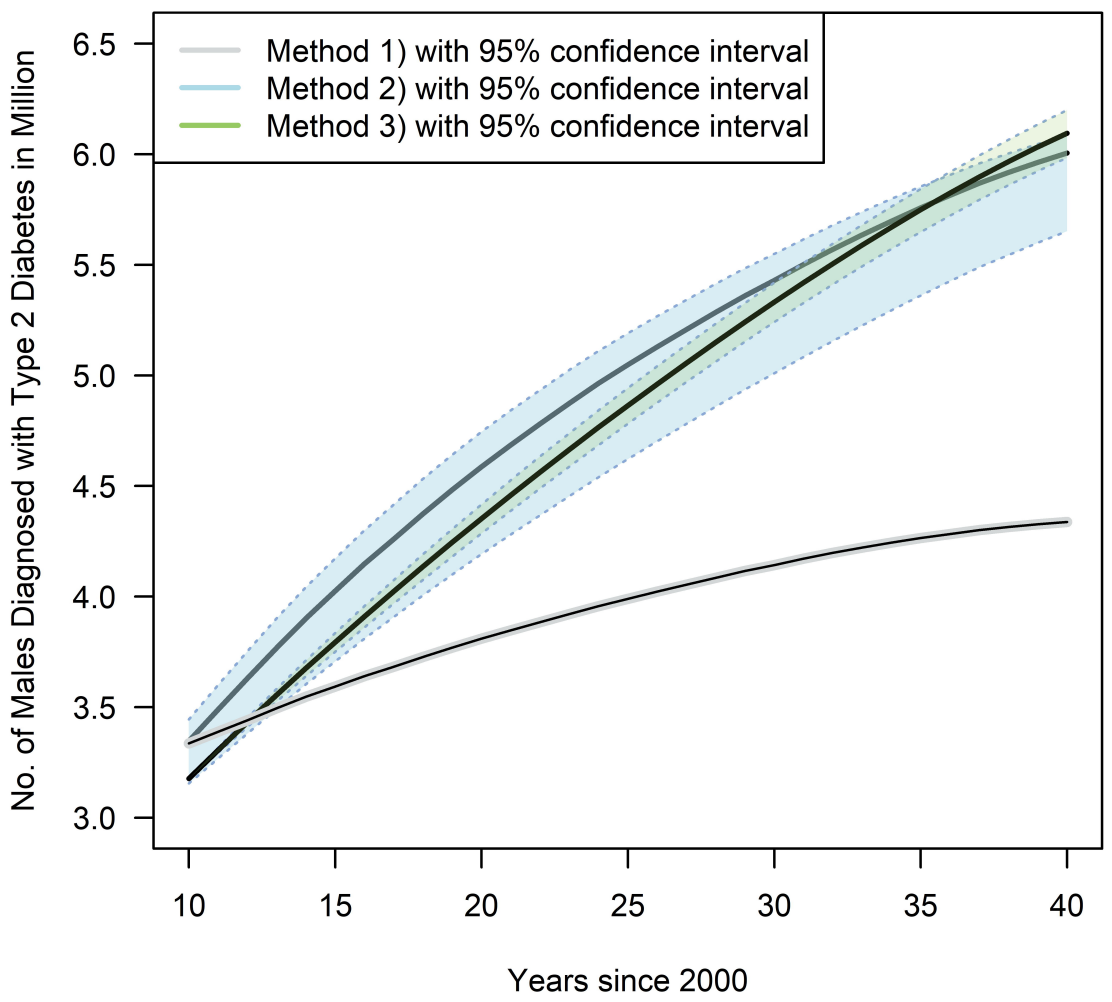

